\title{
Syntax-Semantics Interface: Arabic is a Case
}

\author{
Samir Al Jumaily \\ Postgraduate Department - International University of Islamic Science - London \\ sbrother10@gmail.com
}

\begin{abstract}
In order to make a coherent statement or an accurate description, linguists have to focus on one aspect of a language and preclude the others according to a process called selected focusing b but it is believed that such an act of isolation is only an artificial practice. Although a naïve or a child is not aware of the various levels of language, he/she is well knowledgeable about the grammatical, structural, and semantic tools that make him/her easily and instantly spot the ill-formed or meaningless sentences of his/her native language.

Two opposite mainstreams discovered in the study of syntax-semantics interface. The $1^{\text {st }}$ is the syntactically-oriented perspective established by Chomsky and his followers, which is later modified and supported by the Optimal Theory Approach, and the $2^{\text {nd }}$ is the semantically-oriented one in its two facets- the generative and the interpretive.

The early generative transformational approach went too far in insisting that the syntactic aspect has an autonomous characteristic and should be dealt with in isolation from semantics, whereas others argue that they are interrelated and cannot be separated.

The main objective of this study is to arrive at some general outlines that might help linguists, second/foreign language teachers as well as students and tries to shed light on this linguistic controversy in order to establish a scientific scheme in language studies.
\end{abstract}

Keywords: syntax, semantics, interface, lexical items, generative grammar, semantic, interpretation, transformational rules

\section{Introduction}

The phenomenon of syntax-semantics interface arises from the interactions between the fundamental basics of syntactic organization and that of semantic interpretation. These types of interactions which are constrained in natural language but can be available in all subsystems of grammar. The perception of the syntax-semantics interact process is one of the most interesting and central questions in linguistics. Syntax and semantics go hand in hand and no lexical form without semantical content. Therefore, Lyons (1982:156) confirms that 'the meaning of the constituent lexemes and the meaning of the grammatical constructions that relate one lexeme syntagmatically to another'. Thus, the meaning of the sentence is the product of both lexical and grammatical meaning. In order to illustrate the above mentioned perspectives, see the following examples:

[1] The headmaster saw the teacher.

$$
\text { r r. r. رأى المعلم المدير المعلم. }
$$

[2] The teacher saw the headmaster.

[3] The headmaster saw the student. 
The difference between sentences 1 and 2 above goes to the fact that in the first sentence the lexical item headmaster, its counterpart in Arabic (Al Mudeer) 'المدير', is a subject whereas it is an object in the second. On the other hand, the difference between 1 and 3 is attributed to the difference between the meaning of the lexical items the teacher, its counterpart in Arabic (Al Mu'alim) 'المعلم', and the student, its counterpart in Arabic (Al Talib)' الطالب'.

The grammatical meaning is usually a descriptive one; that is, it can be accounted for in terms of truth condition as illustrated in 1 and 2 above. Yet, Lyons (1982:157) assures 'in some cases the users of language may connect the grammatical meaning with particular social or expressive dimensions'. For instance, French use a singular/plural pronoun distinction in addressing people such as 'tu' and 'vous', and likewise Dutch and German use ' $u$ ' formally to show respect and 'je' informally among friends.

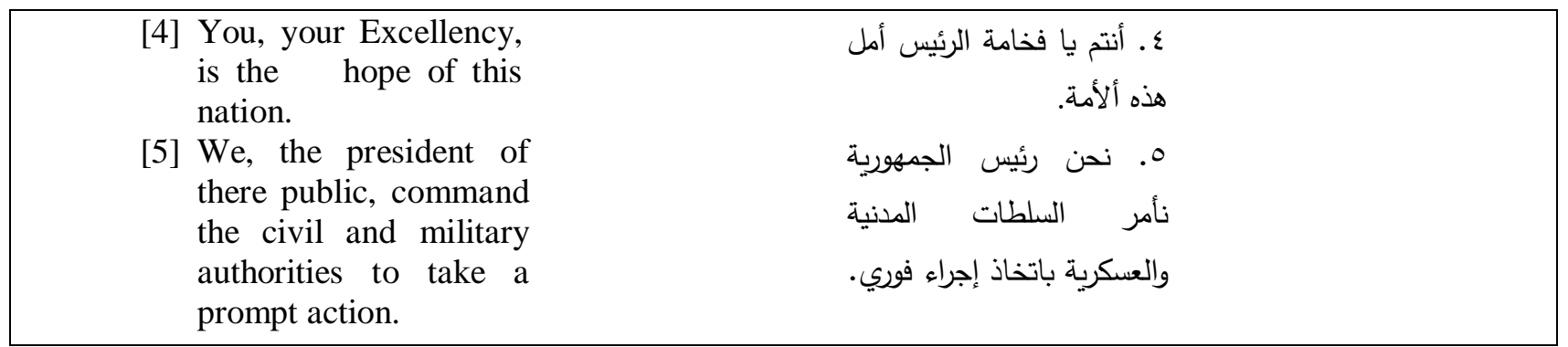

A similar demonstration is found in Arabic exemplified in the following:

The distinction between Lexicon and grammar is the main factor responsible for the difference between what is commonly called grammatical and lexical meaning. In this respect Lyons (1996) states 'the meaning of the sentence ... is determined partly by the meaning of the words of which it is composed of and partly by its grammatical meaning', while such distinction is not always apparent and valid. For instance, there is no clear-cut difference between what Hartmann \& Stock (1972) as well as Quirk, R. et. al (1985) called content words like nouns, verbs, adjectives which have an essential role in transforming the semantic information, and the function words such as articles, demonstratives, expletives which have a more grammatical or functional role.

Furthermore, the distinction between the grammatical and lexical meaning might go to the sense and reference relation. On the basis of the well-known distinction of sense and reference relations of meaning originated by the German philosopher Gotllob Freg in his 1892 paper 'On Sense and Reference', Leech (1976:11-27) presents seven types of meaning; the most important are the conceptual which he defines as the 'logical, cognitive, or denotative content' and associative to which he assigns other five types: Connotative, stylistic, affective, reflected, and collocative.

Lyons (1982:159) handles the difference between the lexical and the grammatical meaning broadly across languages confirming that what is 'lexicalized in one language may be grammaticalized in another'. For instance, the recent actions with a particular effect on the present time is expressed in English by using the present perfect tense, while in Arabic the equivalent conception is expressed by using the simple past tense along with using the verification particle lexeme' لقد attached, sometimes, with an adverb of time. See the sentence below:

[6] Rami has just finished his homework. T. لقد انهى رامي واجبه توا

According to Chomsky (1957:15) and his followers such as Cullicover (1976), there is a clear distinction between the two interrelated conceptions of grammaticality and meaningfulness. Therefore, there are sentences which are syntactically well-formed, but don't make any sense. A 
typical example in this respect is the well-known one (7) composed by Chomsky (1957) and (8) as well:

[7] Colorless green ideas sleep furiously. Or the sentence

[8] The door loves me.

These two sentences (7\&8), in fact, are well-formed syntactically, but ill-formed semantically, whereas the following sentence (9):

[9] Benjamin sents the email,

is semantically well-formed, but syntactically ill-formed.

One more crucial distinction should be made between sentence meaning and the utterance meaning. In this respect, Katz (1981) in his response to John Searle's article (1979) called 'Literal Meaning' denies the existence of sentence meaning totally independent from context and situation; a meaning which might be understood and realized in terms of grammatical or structural considerations alone. To support his perspective, Searle provides the following two sentences:

[10] Cut the grass, and

[11] Cut the cake.

He assumes the meaning of the verb 'cut' in such environment cannot be interpreted without taking into account the speaker's intention as well as the situation since one cannot run the cake with a lawn mower. Although Katz agrees with the importance of the speaker's intention in explaining the meaning of these sentences, he assumes that it is not the speaker's intention that matters, rather it is the distinction between sentence meaning (the grammatical and structural meaning) which might stand alone to reflect the truth and the utterance meaning that depends on particular contexts.

On the other hand, Riley (1985) assumes that if we describe the following utterance

[12] I met the baker's wife,

grammatically, there would be many identical descriptions such as the first person singular pronoun ' $\mathrm{I}$ ', the past tense verb 'met', etc., but if it is described as an utterance, a variety of descriptions corresponding to the various contexts in which it occurs would be required. See the following:

[13] A. Did you get the bus?

B. I met the baker's wife.

Because there is something common (shared knowledge) between the speaker and the receiver, the utterance " $B$ " could be conceived and realized by person 'A' since the baker's wife has a car and provided a lift to person ' $\mathrm{B}$ '.

\section{Different Conceptions of Syntax-Semantics Interface}

\subsection{The Pre-Transformational Prospect}

Robins (1964) assures that traditionalists worked hard and put a lot of efforts in order to provide a kind of semantic description to the grammatical elements and categories. They were inclined to study comprehensively what they called the 'logicization of grammar' or 'speculative grammar' (Dineen: 1969). This type of grammar has studied all aspects of language including the syntactic aspect in the framework of a universal comprehensive theory. The basic principles of the traditional speculative grammar were revitalized by the French teachers of Port Royal who assumed that the structure of the language is the outcome of reason (Lyons: 1979).

The main objection to the traditional perspective regarding meaning and how traditionalists related it to grammar is not because they concerned themselves with it which is a necessary process as it is proved later on, but because their treatment lacked a comprehensive and economical realization of grammatical description.

Structuralists, generally speaking, in their turn emphasized on grammatical theory as well as formal criteria for the establishment of grammatical elements in keeping the status of linguistics as one of the empirical sciences. They assumed that the applied semantics had created various types of obstacles preventing linguists from arriving at a scientific grammatical analysis (Robins: 1964). 
Crystal (1971:208) mentions that Bloomfield, who led the structural school of linguistics in the US in the 1930s and 1940s, did not deny the importance of associating meaning in the descriptive analysis, but considered it a secondary task of a linguist. The immediate constituent analysis (IC analysis), which was primarily adopted by Bloomfield and his followers who were called the 'PostBloomfieldians', was entirely concerned with the identifications and classification of particular constituents in the English sentence.

Great linguists of that period such as Zellig Harris and Charles Fries, whose books were the most typical illustration of the structural approach, gave their entire attention to syntax at the expense of semantics. This point was one of the reasons behind the criticism directed against the PostBloofieldians made by the generative grammarians particularly by Naom Chomsky who assumed that meaning is far more important and central to language to be disregarded although Chomsky himself, as we will notice in the next sections, has not given the semantic aspect a satisfactory consideration (Chomsky 1957 \& 65).

\subsection{The Transformational-Generative Approach}

It is felt extremely necessary to introduce the syntax-semantics interface in terms of the three major versions of Chomsky's Transformational Generative approach discussed in Chomsky (1957, $65,79, \& 81$ ) which he called the Standard Theory, the Extended Standard Theory, and the Revised Extended Standard Theory consecutively. Though all these versions share many common principles, they have undergone several developments particularly in terms of the priority given to syntax over semantics and how these two levels are interrelated.

\subsubsection{The Standard Theory}

Chomsky, in his book 'Syntactic Structures' (1957), focuses on the notion of the independency of grammar. Allen \& Buren (1975) confirm that the two notions of 'grammaticality' and 'meaningfulness' are not associated in any sense. Although the two following sentences are senseless, English speaker can tell that only the first one is grammatical.

- The door speaks English.

- Speaks door English the.

Accordingly, Chomsky (1957:17) concludes that 'Despite the undeniable interest and importance of semantic studies of language, they appear to have no direct relevance to the problem or characterizing the set of grammatical utterances. I think we are forced to conclude that grammar is autonomous and independent of meaning.'

The Standard Theory states that 'a grammar contains a syntactic, a semantic, and a phonological components' as illustrated in the figure below. It is believed that the last two in the sequence are purely interpretative; in the sense, they play no role in sentence generation. The base categorical component generates the deep structures which enter the semantic component receiving the required semantic interpretation.

Chomsky (1965:144) describes the function of semantic component as 'The projection rule of the semantic component operate on the deep structure generated by the base, assigning a semantic interpretation to each constituent on the basis of the readings assigned to its parts and the categories and grammatical relations represented in the deep structure'. Thus, in standard theory, the syntactic component is autonomous with a prior position in comparison to the semantic one.

Since investigating the correlation between syntax and semantics cannot be illuminated with respect to the functions of the two components as it is obvious above, it might be useful to discuss such correlation in terms what Chomsky (1965) calls the 'subcategorization' and the 'selectional restriction' rules keeping in mind both types of restrictions exist in the lexicon which is the major part of the syntactic component.

Radford (1988:369) defines 'subcategorization restrictions are those that govern the categories which a particular item required as its complementation'. Examples:

A. Dative (e.g., send) send [V+NP NP] (2 object noun phrases required), 
B. Intransitive (e.g., laugh) [V -] (no object noun phrases), however, the complementation subcategorized by particular categories are subject to particular restrictions. Check the following sentences:

- Jane tried to persuade her parents to go abroad alone.

- Jane tried to persuade her dog to go abroad alone.

The verb 'persuade' subcategorizes an NP complement; however, there are particular types of NPs restricted by what Chomsky (1965) calls 'selectional restrictions' which are based basically on semantic considerations (Ibid). Crystal (1988) summarizes the Standard Theory Model in the following diagram:

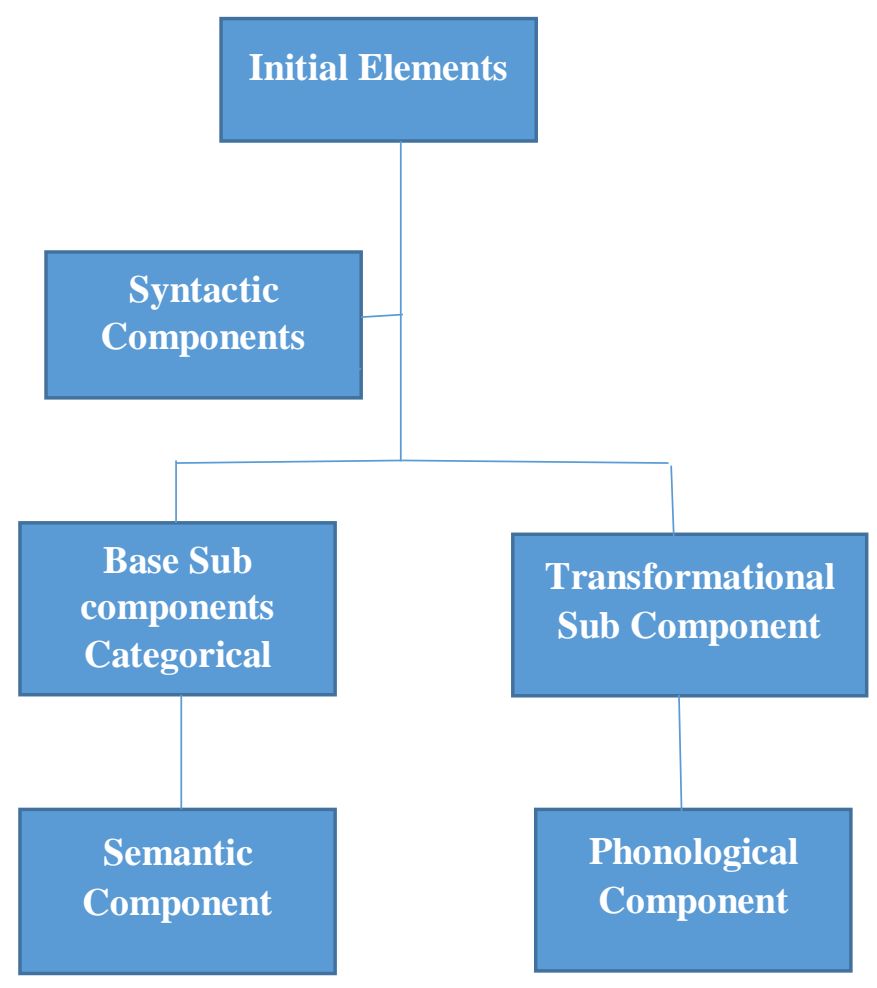

\subsubsection{The Extended Standard Theory}

As usual, linguists try regularly to have their contributions and touches in the field of linguistics and specifically after the emergence of Standard Theory. Some have proved that there are several cases in which transformational rules could not preserve the meaning in several grammatical occasions such as in the use of 'many + negation' as well as anaphoric expressions. For instance, most English speakers would assert that sentences 14 and16 have different meanings in comparison to 15 and 17(Aitcheson: 1987).

[14] Many persons do not drive cars.

[15] Cars are not driven by many persons.

[16] Every candidate voted for every candidate.

[17] Every candidate voted for himself.

Based on such criticism, Chomsky (1972) proposes that instead of having all the rules of semantic interpretation operate on the deep structure, some should take the surface structure as an input. Despite this great modification that gives more significance to semantics, the semantic component has remained interpretative and the generative rules has remained in the syntactic component. Below is a diagram represents the model of the Extended Standard Theory based on Atchison's (1987) perspective. 


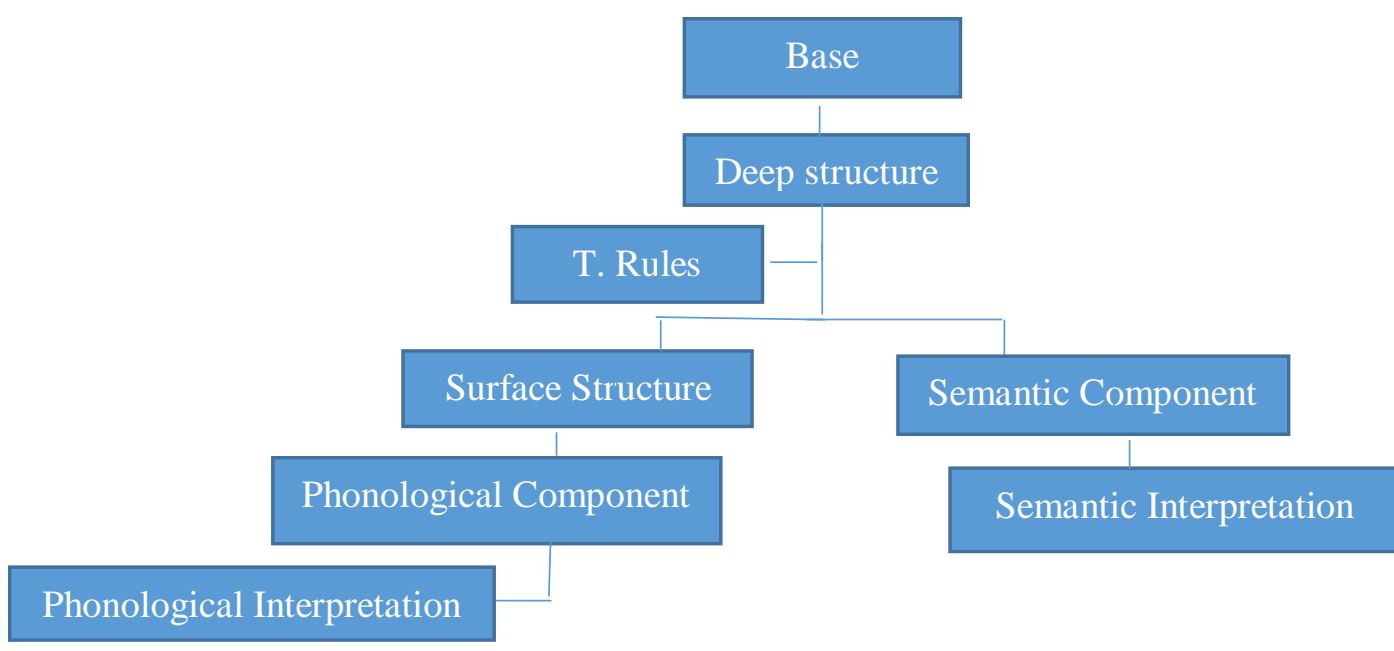

\subsubsection{The Correlation between Thematic and Syntactic Structures in the Recent Version of TG Theory}

With reference to the syntax-semantics interface in TG theory, Chomsky (1981) presents a more crystallized argument wherein he has suggested a particular sub-theory called Theta Theory $(\theta-$ Theory). This theory, which appeared in his book 'Lectures on Government and Binding', examines the essential function of semantics in the overall system and concerned as well with the assignment of thematic roles. See the following:

- Agent: The person or thing carrying out the action.

- Patient: The person or thing affected by the action.

- Goal: The recipient of the object of the action.

For instance, the lexical entry for the verb 'send' in sentence 5 would be:

$[-\mathrm{NP}, \mathrm{NP} / \mathrm{NP}]$ <agent, patient, goal>

[5] Margret sent me an email.

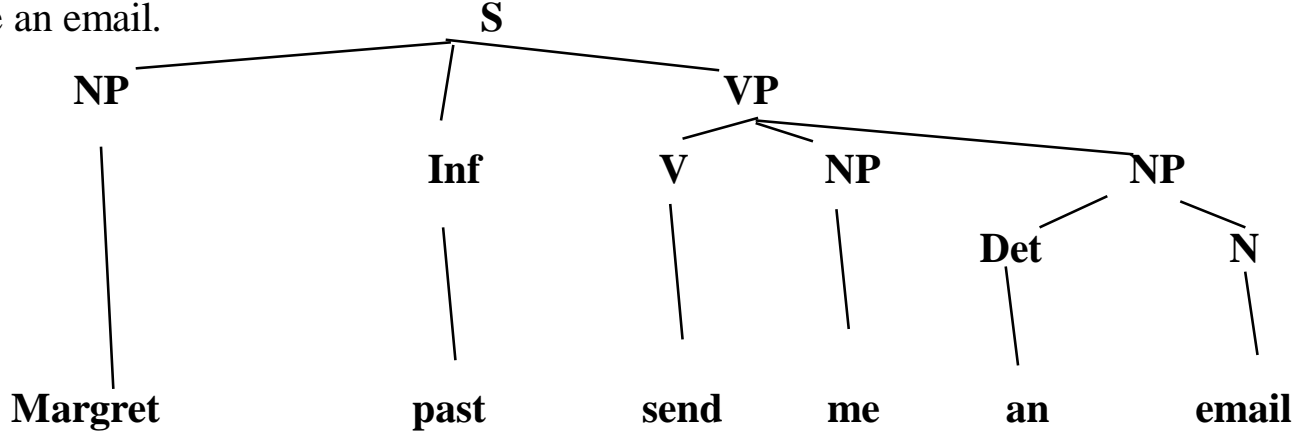

In order for the reader to well understand and realize the GB Theory Model, mentioned above, it is felt necessary to provide a diagram, based on Cook \& Aitchison (1988), summarizes this theory. 


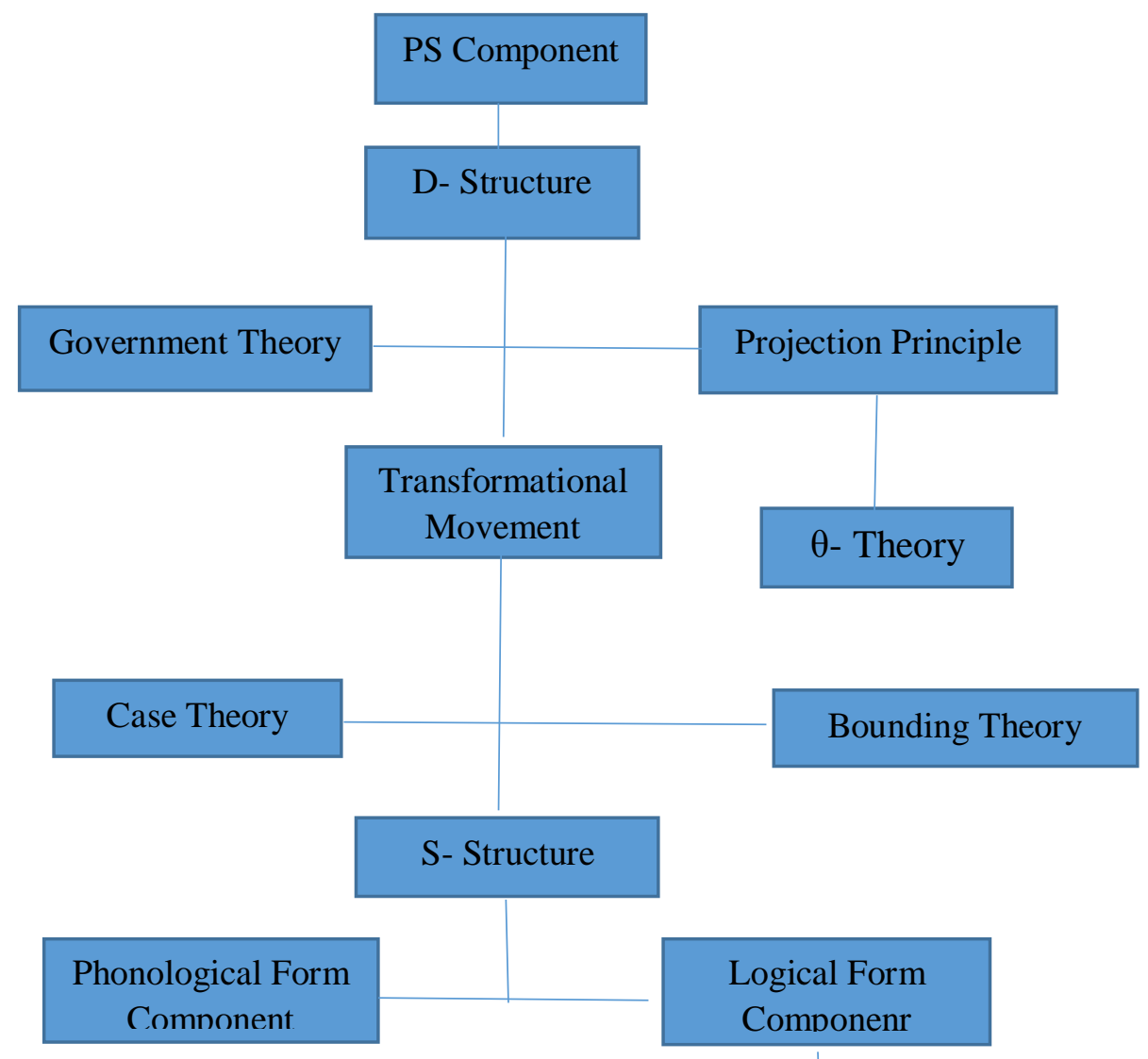

Control Theory

Binding Theory

In addition to the restriction on the syntactic categories of the complements, the lexical entries specify a $\theta$-role restriction. Hence, a lexical entry of a verb $\mathrm{C}$ - Selects the syntactic categories that go with it and also $\mathrm{S}$-selects the $\theta$-roles of these syntactic categories. C-selection and $\mathrm{S}$-selection as two different aspects of Government and Binding Theory are connected by the common factor of government (Cook, 1988:106).

The verb 'send' in the above sentence governs and hence C-selects the NPs 'me' and "an email" as its first and second objects; it, simultaneously, S-selects these two NPs assigning to them "patient" and 'goal' $\theta$-roles respectively.

\subsection{The Post-Chomskyan Approaches}

\subsubsection{Interpretive and Generative Semantics}

Generally speaking, although the generative semantics, which refers to the research done by a number of early students of Chomsky such as Jone Ross, Paul Postal, James McCawley, and George Lakoff (Harris, 1995:105), approved the main principles presented in Chomsky's theory, they denied some certain aspects. Still, they share the assumption that semantics should play a more essential role in linguistic theory (Simpson: 1979).

The first trend was called the 'interpretive semantics' which developed the TG theory conceptions shedding more light on the syntax-semantics interface. Katz and Fodor (1963) assume that a native speaker is equipped not only with an innate ability to distinguish between the wellformed and ungrammatical strings as explained in Chomsky's (1957) but also with the ability of rendering various semantic readings of sentences that share the same deep structure such as:

[18] A. Two books are on the table.

There are at least two things on the table and each is a book.

[19] A. The man was bitten by the dog.

B. The dog bit the man. 
Katz \& Fodor (1963:176) confirm that 'A semantic theory describes and explains the interpretative ability of speakers by accounting for their performance in determining the number and content of the readings of a sentence, by detecting semantic anomalies, by deciding on paraphrase relations between sentences, and by marking every other semantic property or relation that plays a role in this ability'.

The second trend, called the 'generative semantics', went too far in its opposition to the Chomskyan's account of the syntax-semantics interface. Lakoff (1963) who is the most enthusiastic semanticist among his group, differs with his colleagues in the conception whether semantic theory is principally interpretive or generative. He (ibid) states that 'The approach taken by Katz, Fodor, and Postal has been to view a semantic theory as being necessarily interpretive, rather than generative. The problem, as they see it, is to take given sentences of a language and find a device to tell what they mean. A generative approach to the problem might be to find a device that could generate meanings and could map those meanings onto syntactic structures. Lakoff's main objection regarding the interpretative semanticists was sentences like 18 and 19 which have the same meaning but do not have the same deep structure. To support his argument, he provides the following counter-examples: [20] A. I like the book.

The book pleases me.

[21] A. I made that clay into a statue.

B. I made a statue out of that clay.

All in all, the generative semanticists went on working to expand the generative power of semantics in the deep structure to the extent that the underlying and the semantic structures became alike. Accordingly, the base component proposed by Chomsky (1957) was irrelevant, and hence replaced by the semantic representation as illustrated in the figure (Generative Semantics Model based on Leech:1976) below.

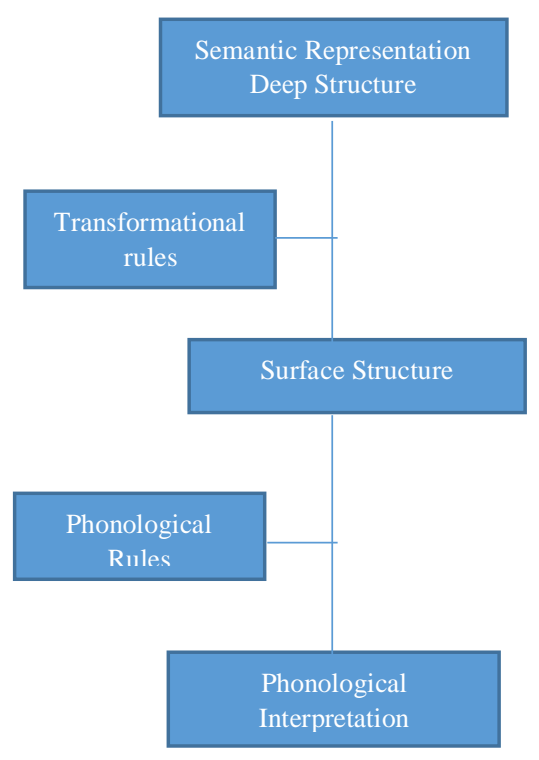

\subsubsection{Case Grammar}

Charles Fillmore, an American linguist, is the originator of this model which initially appeared in a paper entitled 'Case for Case' written in 1968. This paper was an endeavor to classify the verbs with reference to a group of cases submitted by the writer. Cook, who is one of Fillmore's followers in this respect, (1989:35) mentions "although the basic principles of the theory have been preserved by its advocates, some modifications have been proposed by several authors including Fillmore himself'.

Crystal (1988) finds that Fillmore in this matter of "case" went beyond the traditional inflectional variations of nouns and referred to a set of abstract semantic concepts that categorize 
various types of consideration that a man is able to formulate about the antecedents happen around him. Fillmore summarizes his CASES in the table below:

\begin{tabular}{|c|c|c|}
\hline The Title Given to the Case & The Symbol Given to the Case & Semantic Interpretation of the Case \\
\hline AGENTIVE & A & Animate; instigator of the action \\
\hline INSTRUMENTAL & I & Inanimate force or object \\
\hline DATIVE & D & Animate being affected by the object \\
\hline LOCATIVE & L & Location of the action \\
\hline OBJECTIVE & O & Semantic most neutral case \\
\hline FACTITIVE & F & Objects resulting from the actions \\
\hline
\end{tabular}

Fillmore (1975:3) admits that it is not so easy to state any criteria of the priorities of cases in the deep structure, or whether the list of cases he identifies has a clear-cut end, or even the semantic nature of the cases themselves. Therefore, he proposes the following formula in his first paper: 'If an A is present, it becomes the subject: Otherwise, if there is an I, it becomes a subject, otherwise the subject is the O'. The following example, which is cited in Simpson's (1979), illustrates the statement:

[22] John gave (A) the books to my brother.

[23] The books (I) were given to my brother by John.

[24] My brother (O) was given the books by John.

According to Fillmore (1968), all these sentences share the same deep structure; a position that is also taken by the interpretive semanticists discussed above.

As far as syntax-semantics interface is concerned, case grammar emphasizes on the notion that the semantic associations of the cases are obviously of a semantic logical nature rather than of a syntactic one and they should be located in the deep structure as a starting point. Thus, the semantic representations should be considered prior to the syntactic ones in the linguistic theory as illustrated in the diagram, Case Grammar Position, below based on Crystal's (1988) perspective.

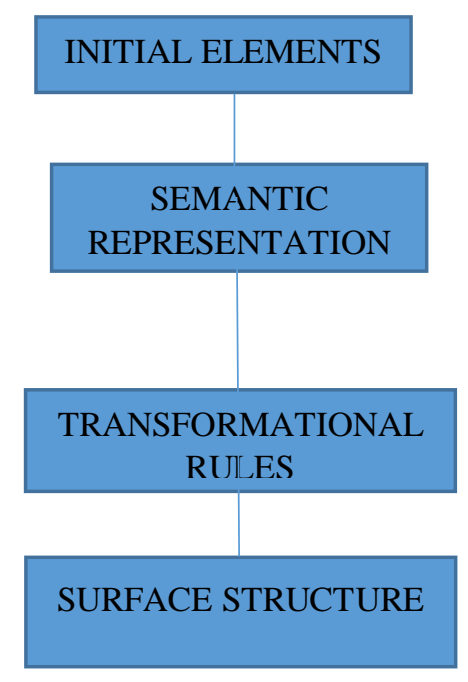

\section{Arabic Model of Syntax-Semantics Interface}

Language is the best tool used for communication through which speakers can express their emotions and thoughts as well as their creative ideas. Therefore, any creative process of any literary genre can be analyzed through lexicons, lexical phrases, semantics and syntax as earlier mentioned. No doubt that a connection is almost always available between semantics and syntax regarding word recognition and arguments establishment in sentences supported by lexical categorizations. The word recognition plays a vital role in the arguments in the form of an utterance which is a complex 
process. Dijkstra (2003:129) states that 'word identification must depend on the characteristics of the lexical item itself, for instance, on how often it has been encountered in the past (e.g. does it have a high or low frequency of usage?), and on whether it is ambiguous with respect to its syntactic category (is dance used as a noun or verb?) or semantics (e.g. does bank refer to the river side or the institution?). In addition a word's recognition process could be affected by the syntactic and semantic aspect of the preceding sentence context which may be more or less constraining or predictive'. The following lines will explain how lexemes are arranged, in Arabic, in a particular order to reveal the semantic interpretation in the sentence. However, if there is any change in this particular order, the sentence will be resulting in an ill-formed sentence.

\subsection{Subject-Object Phenomenon in the Approach of Syntax-Semantics Interface}

As earlier mentioned, the meaning of the sentence is the product of both lexical and grammatical meaning; i.e. 'the meaning of the constituent lexemes and the meaning of the grammatical constructions that relate one lexeme syntagmatically to another' (Lyons: 1982). Therefore, to study and analyze any language, all the linguistic levels should be consideredphonetically, morphologically, syntactically and semantically.

In Arabic, the subject and the object might be problematic to the users syntactically as well as semantically. Syntactically, not every NP that occupies the position of a subject is the true conceptual subject of the sentence. In the sense, it could functionally and grammatically be the subject of the sentence but semantically not. And, this is valid for the object as well. Referring to the true conceptual subject of the sentence, it means referring to the actual doer (agent) of the action semantically as well as syntactically. It is necessary to tell, since the researcher is a native speaker of Arabic, that the verb often occupies the initial position of the sentence in Arabic. If you examine the examples ( $25 \& 26)$ written in Arabic below, the verbs occupy the initial positions of the sentences؛ in the sense, preceding the subjects.

[25] Ali came.

[26] The teacher came in

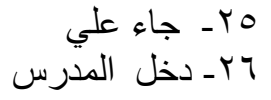

In sentences 13 and 14, the true logical, grammatical and semantical subjects of the deep as well as the surface structure of these two sentences are the lexemes Ali (علي) and the teacher (المدرس) respectively, whereas the NPs (The fence (السياج), Sami (الاناء) (سامي) , the glass occupying the positions of the subject in the surface structure of the sentences $27,28 \& 29$ are conceptually the objects in the deep structures of these sentences.

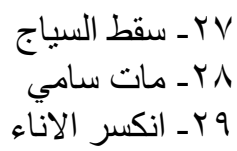

[27] The fence fell down.

[28] Sami passed away.

[29] The glass broke.

Thus, the NPs above are not logically as well as semantically the true conceptual subjects since they are not the real doers of the action. They are just occupying the positions of the subjects on the syntactic level whereas semantically not. In the surface structure, they are the subjects, but in the deep structure, these NPs are objects. These sentences originally are

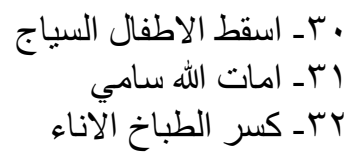

[30] The children brought the fence down.

[31] Allah deadened Sami.

[32] The cook broke the glass. 
In the above three sentences (30,31\&32), the nouns, fence (السياج), Sami (سامي), and the glass (الاناء)) are objects. Thus, the grammatical position cannot solely determine the true subject of the sentence. Accordingly, the semantical categories that decide the true subject as well as the object.

In Arabic, the verb often comes before the subject, and it is considered the major element of the sentence since it expresses the main action. The verb is highly powerful in Arabic due to having the ability to determine what precedes (subject) and what follows (object) syntagmatically. Sometimes and for specific reasons, it is necessary to hide the real subject, and therefore an adjustment in the wording of the sentence is indispensable, in the sense, the arrangement of words in the surface structure is needed. In Arabic, in order to achieve the structure of the passive voice, the form of the verb should be changed from (fa'ala) فَ فُ فُعِل to (fu'aila) which is usually realized in the change of the vowel sounds, along with deleting the true subject of the active sentence and letting the direct object to occupy the position of the subject in the passive sentence. Furthermore, the verb is conjugated for the third person singular in order to agree with the subject. It is necessary to tell that the Arabic sentence does not have a structure equivalent to "by Samir" due to the fact that the doer of the action is supposedly unmentioned. This entirely relies on specific morphological as well as structural changes in the syntactical form of the sentence. The English morphological features as well as meaning understanding could be realized through phonological features, which are called vowels and in Arabic (حركات) (harakaat). Examples:

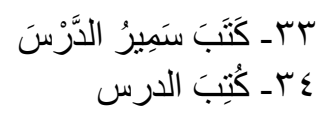

[33] Samir wrote the lesson [kataba (fa'aala) Samir addarsa]. Notice, in Arabic, the verb comes before the subject as in the sentence between two brackets.

[34] The lesson was written by Samir [Kutiba (fu'aila) addrarsu].

The NP, addarsa (the lesson) in sentence 33 is the object, whereas in 34 it is, with the vowel change of the last sound (addarsu), occupying the position of the subject in the surface structure. Structures of the sentences are different but the meanings are the same. In the above examples there are two surface structures but one deep structure or underlying meaning. It means that a sentence can have two or many surface structure but one deep structure. The lexical meaning of words is taken from a bound set of semantic characteristics that correspond in systematic ways to syntactic categories. For some scholars, the interaction between the true subject (agent) and the vowel $/ \mathrm{u} /$ (dhamma (الضمة(1)which expresses a semantic representation, is a type of complementary distribution environment. Below are the tree diagrams of sentence 21 (active sentence) \& 22 (passive sentence) respectively. 


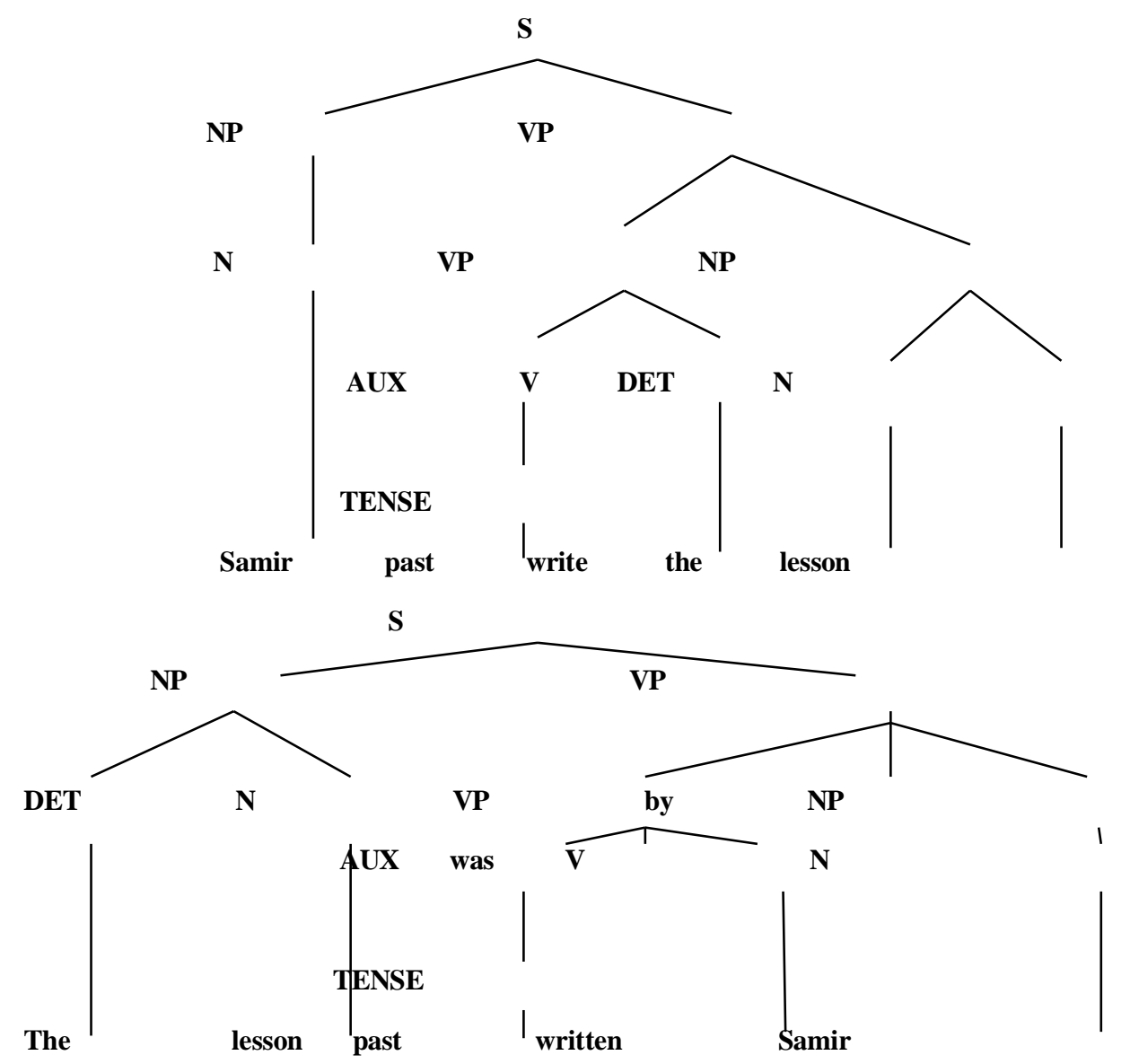

\section{Syntax-Semantics Interface in Optimality Theory Framework}

The making and design of the Optimality Theory (OT) is based on three major components; namely, the generator (GEN), the evaluator (EVA), and a system ranked constraints (CON). These three components work on the basis of the following three principles:

A. A set of language-universal inputs is assumed.

B. The GEN receives theses inputs to generate them into a feasible group of competitive candidates.

C. The EVA receives these competitive candidates and select the optimal output with the help of language-particular constraints (CON).

Thus, the basic generative nature of the morpho-syntactic component proposed by Chomsky in his early theory of TGG is preserved along with the scheme of constraints on the process of transformation which appeared principally in Ross' (1967) 'Constraints on Variable in Syntax' and later developed by Chomsky's (1973) 'Conditions on Transformations'. Consequently, the basic Chomskyan assumption regarding the syntax-semantics interface has continued untouched by Prince \& Smolensky (1993) and the majority of their followers. Yet, some of OT adopters elaborate the functions performed by the above-mentioned components to shed some light on the thorny issue of the syntax-semantics interface.

Beek and Bouma (2004), for instance, challenge the basic theory of the richness of the base proposed by Prince \& Smolensky (1993) assuming that it disregards the role of the lexicon as a 'source of syntactic variation'. Accordingly, they assume that the lexicon should be associated to the GEN component as an 'extra argument' to overcome the consequences of considering the presence and absence of a lexical item as an output of the grammar as mentioned in Samek-Lodovici (1996). Furthermore, Beek and Bouma (2004) criticize the alternative proposal of Noyer (1993) and Kusters (2003) of proposing the inviolable constraint of LEXICALITY and [LEX] since they 'increase the complexity of EVA'. 
On the other hand, Andrews D. Avery ( 2005) proposes what he calls 'glue-logic based semantic interpretation to OT-LFG' in which he develops the basic scheme of the Lexical Functional Grammar in its Optimality Theory perspectives (henceforth OT-LFG) presented by Bresnan (2001). Andrews assumes that it is important to present two kinds of lexicon, semantic and morphological; both of them generates various but related types of input candidates. He sates: 'The splitting of the lexicon will be seen to have some desirable properties in accounting for certain properties of the interface between semantics, syntax and morphology'. As an illustration, he provides the example of the verb 'go' which has the following formal and meaning alternatives:

A. Formal alternatives: / gow/, went/, /go/

B. Meaning alternatives:

[35] Mary went to the store.

[36] The milk went off.

[37] The alarm went off.

[38] Susan went off at the children about the state of the kitchen.

Andrews' (2005) recommended that the lexicon is completely different from the one proposed by Beek and Bouma (2004). Andrews' lexicon is separated to spare a clear-cut division for semantics to generate potential inputs candidates; a position comparable to that adopted by the generative semanticists explained in 2.3.1 above, whereas Beek and Bouma (2004) do their best not to be in opposition to the syntactically-based outlines of OT; they state 'we propose to view a language particular lexicon as an argument in GEN, technically only a small formal adjustment to OT'.

5. Summary of the Findings and Conclusions

This study has arrived at the fact that the subject of syntax-semantics interface is highly controversial and disputable among scholars along the modern history of linguistics, and till now it is not consolidated which judgment is more tenacious than the others. Such uncertainty is due to the fact that all these theories are merely an attempt to describe how language works inside our minds, and hence not subject to any empirical verification.

It sounds that all linguistic theories, except the traditional as well as the structural one, are mainly based on Chomsky's 'Syntactic Structure' (1957) model due to the style of techniques and methodologies practiced along with a number of fundamental notions such as syntax which is the core of grammar and definitely prior to semantics, the generative power of the base component which is subsequently developed into the notion of "the richness of the base" by Prince and Smolensky (1993), and that of the universality of the linguistic theory. The generative and interpretative semanticists along with Fillmore's case grammar could not manage to provide any fabulous reading that might be considered because of the difficulties related to meaning in a similar scientific and formal technique that one might deal with syntax.

Throughout our investigation and dealing with linguistic issues, it has been found that the enigma of syntax-semantics can be moderated if we treat language as a system of encoded by a speaker and decoded by a listener. This assumption is really based on Leech (1979) and backed up by group of recent researchers such as Blunter (1999, 2001), Hendriks \& Hoop (2001), Beaver \& Lee (2003) and Andrew (2005) who try to associate semantics with the recent Optimality Theory in the sphere of language interpretation proposing what they call the "bidirectional" view in language interpretation.

It seems natural that a speaker starts to think first to generate a set of underlying structures which constitute the semantic structure of the sentence he is thinking about. Then, he is obliged to project them via the grammatical rules of the syntactic component in order to have correct phonological interpretation; the speaker-encoding level applies the basic principles proposed by Chomsky and his followers and supported by the serial model of sentence processing suggested by the Garden Path Model of Frazier (1987) and the adopter of the Optimality Theory of Prince and Smolensky (1993) in its away-from-semantics perspective. 
Alternatively, a listener receives, first, the surface structure of the sentence, that is, the phonological and semantic representations, then, passes to syntax in order to arrange and systematize these representations to facilitate the comprehension of their meanings; such an assumption is supported by the generative semantics approach of John Ross, Paul Postal, James McCawely, and George Lakoff, and partly by their counter- researchers the interpretive semanticists adopted by Jerrold J. Katz and Jerry A. Fodor, and partly by Fillmore's case grammar.

\section{References:}

[1] J. Aitcheson, (1987). Linguistics. London: Hodder and Stoughton Ltd.

[2] J. Allen, and P. Buren, (1975). Chomsky's Selected Readings. Oxford. Oxford University Press.

[3] D. Andrews, Avery (2005). Architectures, Rules and Preferences: A Festschrift for Joan Bresnan. Stanford: CSLI Publications.

[4] D. Beaver, and H. Lee. (2003). 'Input-Output Mismatches in OT' in Optimality Theory and Pragmatics by Reinhard Blutner and Henk Zeevat (eds.) 5-7. Palgrave: Macmillan.

[5] R. Blutner, (1999). 'Some Aspects of Optimality in Natural Language Interpretation' in Papers on Optimality Theoretic Semantics by Helen de Hoop \& Henriette de Swart (eds.). Utrecht: Utrecht Institute of Linguistics.

[6] R. Blutner, (2001). 'Two Case Studies in Lexical Pragmatics' in E. Nemeth \& K. Bibok (eds.) Pragmatics and Flexibility of Word Meaning, PP. 11-28. Amsterdam: Elsevier Science.

[7] L. Beek, and L. Bouma, (2004). The Role of the Lexicon in Optimality Theoretic Syntax. Proceedings of the LFG04 Conference Miriam Butt and Tracy Holloway King (Editors) CSIL Publications. http://roa.rutgers.edu/files/690-1004/690-BOUMA-0-0.PDF

[8] J. Bresnan, (2001). Lexical-Functional Syntax. London: Blackwell.

[9] N. Chomsky, (1957). Syntactic Structures. Mouton: The Hague.

[10] ---------- (1965). Aspects of the Theory of Syntax. Cambridge, Mass: MIT Press.

[11] ------------ (1972). Studies on Semantics in Generative Grammar. Mouton: The Hague.

[12] ------- (1973). 'Conditions on Transformation' in Anderson, S. R. (ed.) A Festschrift for Morris Halle (PP. 232-86). New York: Holt, Rinehart and Winston.

[13] ----- (1979). Language and Responsibility. Brighton: Harvester Press

[14] --- (1981). Lectures on Government and Binding. Dordrecht: Foris.

[15] V. Cook, (1988). Chomsky's Universal Grammar/ An Introduction. London: Blackwell.

[16] W. Cook, (1989). Case Grammar Theory. Washington, DC: Georgetown University Press.

[17] D. Crystal, (1971). Linguistics. Cambridge: Cambridge University Press.

[18] D. Crystal, (1988). The Cambridge Encyclopedia of Language. Cambridge: Cambridge University Press.

[19] P. Cullicover, (1976). Syntax. New York: Academic Press.

[20] T. Dijkstra, 2003. Lexical Storage and Retrieval in Bilinguals. Amsterdam: John Benjamins.

[21] F. P. Dinnen, (1969). An Introduction to General Linguistics. New York: Holt, Rinehart and Winston.

[22] Fillmore, Ch. (1968). 'The Case for Case'. In Bach and Harms (ed.): Universals in

a. Linguistic Theory PP. 1-88. New York: Holt, Rinehart, and Winston.

[23] Fillmore, Charles J. (1975). 'An alternative to Checklist Theories of Meaning' in

a. Papers from the First Annual Meeting of the Berkeley Linguistics Society PP.123- 132.

[24] Frazier, Lyn. (1987). Syntactic Processing: Evidence from Dutch in Natural Language and Linguistic Theory 5, PP.519-559.

[25] Gotlob Freg (1892). Über Sinn und Bedeutung', in Zeitschrift für Philosophie und philosophische Kritik, 100: 25-50. Translated as 'On Sense and Reference' by M. Black in 
Translations from the Philosophical Writings of Gottlob Frege, P. Geach and M. Black (eds. and trans.), Oxford: Blackwell.

[26] R. Harris, (1995). The Linguistics War. New York: Oxford University.

[27] R. Hartmann, and F. C. Stork (1972). Dictionary of language and linguistics. New York: John Wiley and Sons.

[28] P. Hendricks, and de Hoop (2001). "Optimality Theoretical Semantics" in Linguistics and Philosophy 24, PP. 1-32.

[29] J.Katz, and J. Fodor, (1963). "The Structure of a Semantic Theory" in Language Vol. 39, No. 2. PP 170-210. Available on line: http: //links.jstor.org/sici?sici=0097

[30] J. Katz, (April 1981). Literal Meaning and Logical Theory in the Journal of Philosophy, Vol. 78, No. 4, PP. 203-233.

[31] W. Kusters, (2003). "Linguistic Complexity; The Influence of Social Change on Verbal Inflection". Ph.D. thesis, Landelijke Onderzoeksschool Taalkunde, Utrecht. LOT dissertation series 77.

[32] Lakoff, George. (1976 [1963]). Toward Generative Semantics. In J. D. McCawley (ed.) PP. 43-61.

[33] G. Leech, (1976). Semantics. London: Penguin.

[34] S. V. Lodovici, (1996). "Constraints on Subjects. An Optimality Theoretic Analysis". Ph.D. thesis, Rutgers University, New Brunswick, NJ.

[35] J. Lyons, (1979). Introduction to Theoretical Linguistics. Cambridge: Cambridge University Press.

[36] J. Lyons, (1982). Language and Linguistics. Cambridge: Cambridge University Press.

[37] J. Lyons, (1996). Linguistic Semantics. Cambridge: Cambridge University Press.

[38] R. Noyer, (1993). Optimal Words: Towards a Declarative Theory of Word-Formation. MS. Rutgers Optimality Workshop-1.

[39] A. Prince, and P. Smolensky (1993). Optimality Theory: Constraint Interaction in Generative Grammar. Boulder, Colorado: University of Colorado.

[40] R. Quirk, G. Leech, and J. Svartvik (1985). A Comprehensive Grammar of the English Language. London: Longman.

[41] A. Radford, (1988). Transformational Grammar. Cambridge: Cambridge University Press.

[42] P. Riley, (1985). Discourse and Learning (Ed.). London. Longman

[43] R. Robins, (1964). General Linguistics: An Introductory Survey. London: Longman.

[44] Ross, R. John (1967). Constraints on Variables in Syntax. (Doctoral dissertation, Massachusetts Institute of Technology). Published in Ross (1986) Infinitive Syntax, Albex. Available on line http://hdl.handle.net/1721.1/15166

[45] J. Simpson, (1979). A First Course in Linguistics. Edinburgh: Edinburgh University Press. 